\title{
Invited Discussion on: Development and Usability of a Virtual Reality-Based Filler Injection Training System
}

\author{
Jonathan $\operatorname{Cook}^{1} \cdot$ Jason N. Pozner ${ }^{1,2}$ (D)
}

Received: 16 July 2020/Accepted: 18 July 2020/Published online: 3 August 2020

(C) Springer Science+Business Media, LLC, part of Springer Nature and International Society of Aesthetic Plastic Surgery 2020

Level of Evidence $V$ This journal requires that authors assign a level of evidence to each article. For a full description of these Evidence-Based Medicine ratings, please refer to the Table of Contents or the online Instructions to Authors www.springer.com/00266.

There is perhaps no better illustration of the importance of virtual training systems than the physical distancing requirements brought about by the COVID-19 pandemic. Although the authors' study slightly precedes this unique societal and cultural backdrop, the authors have recognized an important opportunity for improving the training process for facial filler injection. In their article, "Development and usability of a virtual reality-based filler injection training system," the authors discuss their implementation of a virtual reality (VR) training platform and provide evidence of its usability [1]. We enjoyed this article and appreciate the opportunity to share our comments.

The authors have done an impressive job of designing and implementing the equipment for a novel VR system that tracks the movement of a needle and syringe in three dimensions alongside a model of a human face. These physical components (and their spatial relationships to one another) are then reflected in a virtual display, which provides feedback about the calculated spatial relationship between the needle tip and a virtual model of key facial structures. Although comparatively little information is provided about the development of the physical facial model, we were impressed with the amount of thought and

Jason N. Pozner

jpoznermd@gmail.com

1 Sanctuary Plastic Surgery, 4800 N. Federal Highway, Suite c101, Boca Raton, FL 33431, USA

2 Department of Plastic Surgery, Cleveland Clinic Florida, Weston, FL, USA detail the authors applied in creating the underlying virtual model of the facial vasculature. They have obtained highquality anatomic data from reliable sources, including cadaveric CT scans and MRI. Given the innate variability of facial vessels, the authors chose to focus on "driving plane" (which we understand as "vessel depth") instead of specific vessel location, and we agree with this approach. We also applaud the authors' focus on usability metrics for their system as they continue to develop and implement their technology.

Like many training systems that approximate a "handson" learning experience, the authors' VR training platform is limited by a lack of tactile feedback during use. The authors have done a fair job of explaining this limitation, and they initially planned to implement a representation of facial subcutaneous tissue into their facial model, but ultimately abandoned this effort due to technical limitations. We believe this is the biggest drawback of the authors' training platform: without the tactile sensation of depressing the plunger of a real syringe to inject actual filler, without experiencing the resistance of the product entering the needle, and without observing the subtle expansion of facial soft tissue in response to the placement of product, the training experience will not meaningfully replicate the actual procedure.

Once again to their credit, the authors have recognized this limitation, which is inherent to most (if not all) VR interfaces at the present time. Of course, with advanced technology in the future, there may come a time when haptic feedback can be built into the controller and/or physical interface - in this case, a syringe and facial model. We may eventually come so far that a VR simulation can reasonably reproduce the "hands-on" experience of learning - not just where to inject fillers, but also how to inject. Until then, however, this technology is best 
considered an exceptional training interface for students of facial anatomy. The authors are to be commended for taking this important step in advancing training and simulation in the arena of aesthetic medicine, and their experience will no doubt serve the community well during the time of coronavirus.

\section{Compliance with Ethical Standards}

Conflicts of interest The authors declare that they have no conflicts of interest to disclose.

Human and Animal Rights This article does not contain any studies with human participants or animals performed by any of the authors.
Informed Consent For this type of study informed consent is not required.

\section{Reference}

Oh SM, Kim JY, Han S, Lee W, Kim I, Hong G, Oh W, Moon H, Seo C (2020) Development and usability of a virtual reality-based filler injection training system. Aesthet Plast Surg. (in press)

Publisher's Note Springer Nature remains neutral with regard to jurisdictional claims in published maps and institutional affiliations. 